\section{Social Inclusion and Exclusion: A Review ${ }^{1}$}

\section{Nabin Rawal}

\begin{abstract}
The concept of social exclusion/inclusion figured prominently in the policy discourse in France in the mid 1970s. The concept was later adopted by the European Union in the late 1980 s as a key concept in social policy and in many instances replaced the concept of poverty. This concept which had first appeared in Europe as a response to the crisis of the welfare State has now gained considerable currency over the last five years in both official and development discourses in Nepal. The issue gained considerable leverage when the Nepal Government recognized inclusion as a policy issue as one of the four pillars of 2003 Poverty Reduction Strategy Paper (PRSP), which is also Nepal's Tenth Plan. The debates surrounding inclusion/exclusion have ascended to conspicuous importance in the present political transition in Nepal with several groups such as Dalit, women, ethnic communities, donor communities, Madhesi communities and region voicing their demands for an inclusive state by virtue of which, the issue has now come to be a part of the popular public discourse. However, what has to be borne in mind is that the concept lacks universality in the way it has been defined and employed. While some claim that social exclusion is more illuminating and holds the promise of understanding disadvantaged groups better, others argue that this concept is so evocative, ambiguous, multidimensional and elastic that it can be defined in many different ways and owing to its ambiguity in definition it may
\end{abstract}

${ }^{1}$ A review of social inclusion and exclusion is limited to the literature available to the reviewer. mean all things to all people. Howsoever, the term has been used, defined, conceptualized, the article here makes an effort to review accessible literature on the topic.

\section{Introduction}

René Lenoir, writing about a quarter of a century ago, is given credit of authorship of the expression. As Secrétaire d'Etata l'Action Sociale of the French Government, René Lenoir, spoke of the following as constituting the "excluded"—a tenth—of the French population:

mentally and physically handicapped, suicidal people, aged invalids, abused children, substance abusers, delinquents, single parents, multi-problem households, marginal, asocial persons, and other social 'misfits'.

The literature that has followed Lenoir's original initiative has vastly added to this already bulging list of the "socially excluded" and is seen as covering a remarkably wide range of social and economic problems (Sen, 2000:1). The concept of social exclusion as it appeared in France and Europe in general, was tied to the effect of the failure of integrative institution. As Room (1995, cited in O’Brien and Penna, 2007:3) points out, the concept has its roots in the functionalist social theory of Emile Durkheim. Writing at the turn of the $20^{\text {th }}$ century Durkheim was concerned with how social order and stability could be maintained in a society where social dislocations accompanied the transitions from an agrarian to industrial society. O’Brien and Penna (2007) argues that the concept of social exclusion and the contemporary European research agenda on it has been informed by the problems associated with maintaining social order and stability. Durkheim's moral sociology echoes down the centuries, and much greater significance has been a rerendering of Durkheim - in the resurgence of neo-Parsonian 
systems analysis and 'neo-functionalism'- in sociology and social policy analysis from the late1970s onwards. (O’Brien and Penna, 2007:3)

This concept, which first emerged in the policy discourse in France and its adoption later by other European countries have had an increasing impact on the analyses of social disadvantages in Europe over the last couple of decades. (Aasland and Flotten, 2000:1026; Gore and Figueiredo, 1997, cited in Francis, 2002:74).

The concept gained widespread applicability after the World Summit as a result of which, increasing attention has been paid to the possible relevance of the concept to social policy analysis in developing countries (IILS, 1997, IDS, 1998, cited in Kabeer, n.d.:1), and it was widely adopted by development agencies and in development studies as another way of understanding and reducing poverty in the south (Jackson, 1999:125). It has also been argued that the application of social exclusion to southern societies is indicative of a convergence of social policy between North and South as a result of globalization and international migration (Maxwell, 1998, cited in Francis, 2000:75). Thus, the danger is that given the roots of the concept in northern policy discourse, it will simply serve to re-label longstanding and locally developed approaches to social problems or alternatively, that it will promote a tendency to assess southern realities in terms of the extent to which they converge or diverge from some 'standard' northern model (Kabeer, 2000:2). Likewise in similar vein, Silver (1995) has argued that the meaning of social exclusion depends on the nature of the society, or the dominant model of the society from which exclusion occurs and it varies in meanings according to national and ideological contexts (Silver, 1994:539).

\section{Conceptualizing Social Exclusion:}

Social exclusion has been defined as 'the process through which individuals or groups are wholly or partially excluded from full participation in the society within which they live' (European foundation, 1195, p.4, quoted in de Haan, 1998, cited in Francis, 2002).

Aasland and Flotten (2000) state that the concept of social inclusion gained prominence in the policy discourse in Europe since it replaced the concept of poverty, taking into its fold more dimensions of people's lives than the poverty concept.

An important reason for this is the fact that the concept of poverty has been difficult to define, and that it has been heavily contested whether or not this concept can fully depict the social disadvantages in today's society. One of the most popular arguments in favor of the social exclusion concept is that it takes into account more dimensions of people's lives that the poverty concept (Aasland and Flotten, 2000:1027).

However, Aasland and Flotten (2000) argue that the concept of social exclusion is no more unambiguous than the concept of poverty. They contend that when the concept was first employed in France in the 1970s, it took into account people unable to adjust to mainstream society and the following years the concept was frequently redefined and more groups were included, such as school dropouts, unemployed youths and immigrants (Aasland and Flotten, 2000:1027). Thus Aasland and Flotten, attribute the problematic attached to the concept of social exclusion as arising out of the increasingly varied meaning attached to it in France and its spreading to other countries with their own interpretations of the concept. Furthermore, they argue that the concept is vague and is employed to describe a multitude of situations and processes, 
which is often loaded with economic, social, cultural and political connotations. In order to operationalize the concept of social exclusion adequately for empirical analysis, they have made an effort to present an analysis of the relationship between ethnicity and several variables that they consider to be proxies for social exclusion.

They consider social exclusion as multidimensional phenomena and have considered several important living condition variables as proxies for social exclusion. They are: 1) Exclusion from formal citizenship rights: 2) Exclusion from labor market; 3) Exclusion from participation in civil society and 4) Exclusion from social arenas. Participation in all these arenas would suggest that people are not socially excluded, but indicators of participation, degree of participation, and how degree of participation in different arenas should be considered in relation to each other still need to be specified. (Aasland and Flotten, 2000:1028).

Francis (2000) locates the strength of social exclusion as a concept in its attempt to capture the multifaceted character of social deprivation, especially its institutional and cultural aspects. This conception of social exclusion has been labeled as multidimensional concept of exclusion (Geddes and Benington, 2001, cited in O’Reilly, 2005: 81). The strength of the concept according to Francis lies in the fact that in distinction to poverty, which has been primarily thought about in economic terms, social exclusion also takes into consideration deprivation in number of spheres, of which low income is but one. However, he states that there are three questions that are of vital importance in order to assess the concept of social exclusion. First, how does it differ from that of poverty? Second, what does it add to our understanding of deprivation? Third, does it increase our capacity to address such social ills? (Francis, 2000:75)
According to Geddes and Benington, (2001), the multidimensional concept of exclusion broadens out the notion of material poverty and identifies social problems and then labels them as aspects of social exclusion. Geddes and Benington (2001) argue that this approach to exclusion is naïvely heuristic and tautological in that it identifies social problems and then labels them as aspects of exclusion. It is not guided by any particular social science paradigm or theorization of what either exclusion or inclusion is. Its lack of theoretical rigor, however, means that the absence of a strong ideological orientation allows a relatively open approach to identifying exclusion, even if its symptoms and conditions are not systematically understood (Geddes and Benington, 2001, cited in O’Reilly, 2005:81)

Sen (2000) argues that the idea of social exclusion needs to be examined in relation to its utility in providing new insights in understanding the nature of poverty, identifying causes of poverty, contribution to thinking on policy and social action in alleviating poverty. Sen (2000) associates idea of social exclusion to capability perspective on poverty (Sen, 2000:4).

The capability perspective on poverty is inescapably multidimensional, since there are distinct capabilities and functionings that we have reason to value. I would suggest that it is useful to investigate the literature on "social exclusion" using this broadly Aristotelian approach. The connections are immediate. First, we have good reason to value not being excluded from social relations, and in this sense, social exclusion may be directly a part of capability poverty. Second, being excluded from social relations can lead to other deprivations as well, thereby further limiting our living opportunities. For example, being excluded from the opportunity to be employed or to receive credit may lead to economic impoverishment that may, in turn, lead to other deprivations (such as undernourishment or homelessness).Social exclusion can, thus, be 
constitutively a part of capability deprivation as well as instrumentally a cause of diverse capability failures. The case for seeing social exclusion as an approach to poverty is easy enough to establish within the general perspective of poverty as capability failure (Sen, 2000:4-5).

Even though the concept of social inclusion has its roots in France, Hillary (1994) states that in contrast to distinctive French Republican conceptions, challenges to Republican ideology and the adoption of exclusion discourse in other national contexts imparted meanings to the term more properly considered within other paradigms of social disadvantage (Hillary, 1994:539). Thus, in Social exclusion: Three paradigms (1995), she puts forth her threefold typology of the multiple meanings of exclusion distinguished by different theoretical perspectives, political ideologies and national discourse. The three paradigms of social exclusion viz: solidarity, specialization and monopoly, based on different notions of social integration, attributes exclusion to a different cause and is grounded in a different political philosophy and provides an explanation of multiple forms of social disadvantage.

The 'solidarity' paradigm derived from the French Republican thought attributes exclusion to the breakdown of social solidarity i.e. the social bond between the individual and society. The solidarity paradigm, with strong antecedents in Durkheimian sociology, views society as something external, moral and normative rather than grounded in individual, group or class interests and solidarity arising out of shared values and rights. This approach lays heavy emphasis on the ways in which cultural or moral boundaries between groups socially construct dualistic categories for ordering the world. Like deviance, exclusion both threatens and reinforces social cohesion and the inverse of exclusion is 'integration' and the process of attaining it is insertion, which implies assimilation into the dominant culture.
As Paul Spicker (cited in Atkinson and Davoudi, 2000) points out, however, there are two variants of the social integrationist discourse: the one Levitas identifies as a 'new Durkheimian hegemony' that justifies differences between groups, and a more republican version that identifies solidarity as transcending individual, class, ethnic and regional interests (O’Reilly, 2005:82).

The specialization paradigm, indicative of the Anglo-Saxon world, in contrast, is one of social differentiation. The AngloSaxon liberalism assumes that individuals differ; giving rise to specialization in market and in social groups and thus views the social order as networks of voluntary exchanges. The liberal tradition emphasizes the contractual exchange of rights and obligations and the separation of spheres in social life. Thus, according to this paradigm, exclusion is a form of discrimination, which occurs when individuals are denied free movement and exchange between spheres, when rules inappropriate to a given sphere are enforced or when group boundaries impede individual freedom to participate in social exchanges.

The third paradigm, influential on the European Left, views exclusion as a consequence of the formation of group monopolies, with resoures being controlled by hierarchical and exclusive networks. Drawing heavily on Weber, and to some extent Marx, it views the social order as coercive, imposed through a set of hierarchical power relations. According to this paradigm, exclusion arises from the interplay of class, status and political power and serves the interest of the included and the excluded are simultaneously outsiders and dominated. Exclusion can be combated through citizenship and the extension of equal membership and full participation in the community. 
According to Levitas (1998) the redistributionist moral discourse that accompanies the monopoly paradigm prefigures inclusion in terms of citizenship rights which would promote equality (Levitas, 1998, cited in O'Reilly, 2005:82). The utilization of a discourse of rights as a tool for social change has been challenged by the responsibilities discourse of neo-conservative parties and commentators, while the monopoly paradigm implies that a restructuring of the economy is necessary to change the unequal distributions within society to which current social rights are only a palliative (O’Reilly, 2005:82).

Even though Hillary Silver has tried to locate her paradigm of exclusion based on the nature of society, nevertheless, such differentiated conceptions of the nature of society would entail different notions of what exclusion and inclusion would really mean. This paradigm based on the nature of society calls for different conceptions of what constitutes inclusion and exclusion, thus, making it even more difficult to devise a suitable means for promoting inclusion. In the same light Jackson (1999) also argues that dualistic opposition between inclusion and exclusion tends to emphasize exclusion as the opposite of integration, which limits exploration of the contradictions in the multiplicity of exclusion or the paradoxes of simultaneous inclusion and exclusion.

Even at the level of a single society, the concept, by presenting forms of social differentiation in terms of a single descriptor, implies that the various groups that make up the 'excluded' may have more in common than is in fact the case (Francis, 2000:76). Francis (2000:76) further adds that the mechanisms that create and perpetuate disadvantage among, for example, the disabled, women, scheduled castes, pastoralist, the landless, the Roma and the industrial employees are very different and whatever the superficial attraction of a common schema, placing these groups in a single category may do little to aid the understanding of the specific difficulties that any of them face, or to help resolve these. A case in point has been illustrated by Jackson (1999) where she argues that early liberal western feminisms produced a universalizing theory of marginality, which tended to view the marginality of women as 'parallel in its form to the marginalized of the colonized, the non-white, or the poor' (Tsing, 1993:18, cited in Jackson, 1999:130) which failed to take into account the divisions between women, and the fact that gender marks social relations across and within groups. This position shifts the focus on the gendered construction of identities rather on a bounded category of exclusion based on gender.

She further argues that a binary and polarized formulation of inclusion and exclusion is problematic for at least two reasons. First, it suggests a unitary notion of power in which the included are powerful and excluded are powerless, rather than one in which power is dispersed, contingent and unstable. Second, dualist discourses can themselves be structures of control, which deserve to be questioned and decentered (Jackson, 1999:132.).

Cursory reviews of the concept of social exclusion clearly indicate different conceptions of what constitutes social inclusion and exclusion. The concepts and definitions vary both in the academia and in development policies. For instance, some analysts see social exclusion as a cause of poverty, others suggest that it is both an expression and a determinant, of poverty and most would probably agree that poverty is a form of social exclusion (de Haan, 1998, cited in Jackson, 1999:126). Although, originally defined in terms of the rupture of social bonds, and applied to social disintegration rather than poverty per se, social exclusion has developed in a range of paradigmatic styles in different political and intellectual contexts (Silver, 1995, cited in 
Jackson, 1999:126). In development discourse, social exclusion is discussed predominantly in terms of its relationship to poverty. Is it a cause or consequence of poverty or cause of poverty? Is it a better way of conceptualizing poverty? How does it differ from other ways of conceptualizing poverty? (de Hann, 1998, Gore and Figueiredo, 1997, cited in Jackson, 1999:126)

Furthermore, inclusion and exclusion are inseparable sides of the same coin: the strength of intragroup ties and of the identity that forges them is inseparable from a community's definition of itself as distinctive. And if inclusion implies, as it may, incorporation into exploitative or violent relationships, exclusion may not always be a bad thing (Francis, 2000:76).

Given this variations on the conception of exclusion, Francis (2000) contends that the notion of social exclusion, while carrying a number of pointers for a broader and less incomefocused conception of generation is not a very precise or a nuanced one (Francis, 2000:76). Indeed one may suspect with Atkinson (1998:13) that it has gained such wide currency partly because it means all things to all people.

\section{Social Inclusion}

A review of the limited literatures accessible to the author has shown that social inclusion has not been defined in its own right. In literatures conceptualizing exclusion, conceptions of inclusions are implicit and unproblematized. In fact, social inclusion is seen to be defined in relation to social exclusion. Some analysts have argued that both inclusion and exclusion are inseparable side of the same coin. However, some comment that academic debate on social exclusion has been relatively silent on its assumed corollary.

There have been some notable contributions to a debate on inclusion (cf. in particular the essays in Askonas and Stewart, 2000), but this has not been closely integrated into the wider debate on exclusion. It therefore remains the case that in the majority of the exclusion literature the nature and meaning of social inclusion is merely implied or asserted (Cameron, 2006:396). Only if the question of what constitutes inclusion is addressed can the question of what constitutes exclusion be posed. Each question is mutually dependent on the other. (O’Reilly, 2005:84)

Cameron (2006) further argues that due to an inadequate understanding of what is meant by inclusion, the attention has been focused on the problems and deficits of "excluded" (Cameron, 2006:397). He deplores the way by which the issue of inclusion has been taken up in reference to the debate of exclusion, but fails to provide his own conceptualization on the issue. He alluded this shortcoming to a result of a general failure to develop a critical understanding of the real and discursive geographies of social inclusion. For instance, he remarks,

Where a conceptualization of inclusion does appear in the social exclusion literature, it is often only indirect. Frequently, for example, it appears in invocations of 'normal' social expectation/participation or, more commonly,' mainstream' applied to various things that people are understood to be excluded from: labor market, economy, society, culture, citizenship, etc. The meaning and location of the mainstream is routinely taken to be self-evident. As this implies, social inclusion is most commonly defined only negatively as whatever is not socially excluded. For this reason, much of the discussion of social inclusion is conceptually dominated by exclusion - social exclusion is the datum point against which social inclusion is both empirically measured and conceptually defined (Cameron, 2006:397)

Despite the fact that social inclusion has been defined with regards to social exclusion in many of the literatures, Jackson (1999) argues that there can be simultaneous exclusion and 
inclusion, that is individuals and groups can be excluded in one domain and included in another, for instance, "social relations of kinship and marriage include whilst they exclude and affirm, as they deny membership rights' (Jackson, 1999:129). One can thus talk about inclusion in the domain of language but exclusion in political and economic domains, e.g. in the case of parbate Dalits; or exclusion from the dominant language and culture but inclusion in political and economic domains, as in the case of Newars (Pradhan, 2006).

Likewise, Jackson (1999:130) drawing on the works of marginality by Anna Tsing (1998:18) argues that marginality is both a source of constraint and creativity. Marginality offers both limitations and opportunities, for instance, women can use the idioms of motherhood and the domestic as the basis for voice. Jackson (1999) quoting the work of Tsing (1998) on the Meratus women of Indonesia reveals that gendered experience of marginality in which, 'as one moves closer to powerful centers, one gains both luxury and servitude; as one moves away, one gains autonomy with hardships.

Feminist inquiries have also shown that marginality need not only be a social disadvantage but can be both the ground of resistant discourses and resource claims. For example, in a piece on women irrigators in Nepal Margareet Swarteveen and Nita Neupane (1996, cited in Jackson, 1998) have shown that identities of exclusion and vulnerability were utilized to argue successfully for priority in water supply, to justify 'stealing' of water, to avoid night irrigation, to win exemption (on grounds of lesser strength and the undesirability of women working alongside strange men) from contributing to system construction and maintenance and reduction in cash contributions (Jackson, 1998:131). Thus, if inclusion implies, incorporation into exploitative or violent relationships, exclusion may not always be undesirable. More important is the ability of individuals and groups to control the terms under which they are included. For instance, debates about marginality have deep roots in Latin America where poverty is seen as resulting not from lack of integration the world capitalist system, but rather from the terms of incorporation of individuals and communities within it (Gore, 1995:5, cited in Jackson, 1999:128)

Jackson (1999:135) also reminds us that inclusion can also produce exclusion, and this occurs, when excluded groups successfully achieve inclusion on the basis of excluding groups even weaker than themselves. For example, women may deny their gender interest in bid for inclusion through adopting male postures or the socially mobile poor may position themselves nearer the center through dissociation from the seriously poor. As Pradhan (2006) claims that for social inclusion have been frequently made by constructing an excluded other in Nepal. However, many ethnic groups discriminate against the Dalits, and upper caste women discriminate against low caste women. He also argues that the hill ethnic groups and Dalits may achieve inclusion into the state structures by excluding the Madhesis, especially those who are neither Dalits nor adivasis/janjatis.

Thus, the included/excluded dualism apparent in the writings of social inclusion and exclusion cannot be taken at face value. The politics of dualistic inclusion/exclusion deserve questioning in other ways. One of these is to consider in what sense there is a single centre of social integration, who is excluded from what, and whose representation of the centre is privileged (Jackson, 1999:133). She further notes that representation of both the included and the excluded need to be critiqued. Jackson (1999:133) drawing on Fraser (1997:75) argues that, in $19^{\text {th }}$ century America, 'the view that women and blacks were excluded from "the public sphere" 
turned out to be ideological; it rests on a class and genderbased notion of publicity, one that accepts at face value the bourgeois public's claim to be the public. Pradhan (2006) also cautions against taking the arguments at face value, where he writes, 'to say that the janjatis, Dalits, women and Madhesis are excluded and thus have to be included, without adding further qualifications, may be politically correct and useful for research and project grants, but it does not really help us to understand the complexities of the relationships between exclusion and inclusion”.

\section{Inclusion/Exclusion Debate in Nepal}

The inclusion/exclusion debate has now pervaded both the official and development policy discourse in Nepal. Inclusion as an official policy made inroads into the government policy after inclusion was incorporated as one of the four pillars of Nepal's Poverty Reduction Strategy Paper (PRSP) in 2003, which is also Nepal's Tenth Plan. Contemporarily, inclusion, state restructuring, proportionate representations, federalism are the recurring themes in today's public discourse in Nepal.

The resurgence of ethnic identity was fortified after the reinstatement of multiparty democracy in 1990. Along with ethnic revivalism, issues and grievances of the Madhes were also spearheaded by political parties, mainly the party which had its electoral base in the Madhes. However, with the current change in regime after the popular uprising in April, which has been dubbed as Janandolan-II, cultural, ethnic, linguistic and even territorial claims have boiled over with intensity, hitherto unknown.

The ethnic groups, the Madhes and Dalits have now challenged what they call the hegemony of the parbatiya hill 'high' castes. Ethnic groups in particular have rejected and come down heavily on what they call the process of
Hinduization $^{2}$, which according to them have relegated them to the margins. They have called for proportionate representation and ethnic autonomy with the right to selfdetermination. Likewise, the grievances of the Madhes that have now surfaced after the success of the Janandolan-II are not new either. Long back, Gaige (1975) had argued with reference to the Tarai region that Nepal had been geographically united; however, the State had not been able to accommodate the aspirations and culture of the Tarai in the national framework. Gaige (1975:195) had then stated that integration of the Tarai in the national framework by force is not a viable option, but a more realistic approach would be to draw the plains people into the national structure through participation in the nation's political life, through encouragement of the voluntary acceptance of national political and cultural values. Likewise, Dalits in both the hill and Tarai face the brunt of the discriminatory practices prevailing in Nepal, since, it is a common practice whereby non-Dalits, including both caste and ethnic communities in both the hill and Tarai regions as well as in rural and urban settings, exclude Dalits.

There is no doubt that the cultural and linguistic rights of the ethnic communities have been denied by the State. Nevertheless, what I would like to argue is that, it would be wrong to treat the issue of exclusion in a simplistic manner or understand it through the binary opposition of exclusion/inclusion. Thus, it is imperative that the issue be discussed and debated by identifying the variations amongst the social sub-categories within the caste and ethnic population as well as between members belonging to them. Available literature in Nepal on social discrimination/ exclusion/inequality has paid little attention to this. Rather, it puts forward an argument that the Brahmans and Chhetris are

\footnotetext{
is a process of social ordering according to the Hindu framework
} which is typically based on a hierarchy of caste 
the most privileged among all caste and ethnic communities and they have remained in positions of power and have used this privilege to shape the system of values in society as well as to divert its opportunities and resources in favor of their own communities (Pandey et.al., 2006:76). This type of perception has been expressed in the metaphor of what has been commonly termed as 'Bahunbad' (Bista, 1992).

At a broader level of generality, these arguments are not unfounded. Nevertheless, Nepal's caste and ethnic population constitutes a number of diversities, and internal variations among different ethnic communities also exist. Data available for the case of Newars and Thakalis indicate that, unlike what has been said about the ethnic population and indicative of the discourse on exclusion/inclusion, the share of these two ethnic groups in the opportunities and facilities available in the country is higher than any caste group or any other ethnic community. This it true to their share in graduate population, urban population, business transactions, technical, legislative, administrative and clerical jobs in governmental institutions, income levels and access to other facilities (See Pandey et.al:77). Such a context also enables us to be aware of the limitations associated with perceiving caste and ethnic population as homogenous categories.

Thus, the debates of inclusion/exclusion in Nepal have not taken into account the differences in terms of the proportion of privileged population contained within each group, which indicates that 'other' analytical categories of comparison should be formulated while indicating the extent of inclusion or exclusion in Nepal.

\section{Conclusion}

The concept of social inclusion/exclusion emerged in response to the crisis of the welfare state in Europe, which had an increasing impact on the analysis of social disadvantages in Europe over the last couple of decades. When the concept was first employed in France in the 1970s, it took into account people unable to adjust to mainstream society and later other European countries adopted it with their own interpretation. The concept gained widespread applicability after the First World Summit on Social Development in Copenhagen in 1995 as a result of which, it was embraced into the development discourse and development agencies. Likewise, inclusion was also incorporated in the official policy discourse of Nepal in 2003, after which, the issue has gained considerable currency. However, Nepal's tryst with the concept should also be understood in the broader context of policy discourse that surrounds official development agencies, and its considerable leverage in the development policy of Nepal.

As is seen social exclusion/inclusion is contestable term, and thus its relevance to Nepal in its European avatar is open to a lot of questions. Furthermore, given the diversities in Nepal, with its own social, cultural, historical realities, the concept needs more deliberation and needs to reflect the realities of Nepal going beyond popular discourse and emotive appeal for a segment of the population.

\section{Reference}

Aasland, A and T. Fløtten (2001). "Ethnicity and Social Exclusion in Estonia and Latvia" in Europe-Asia Studies, Vol. 53, No. 7. (Nov., 2001), Pp. 1023-1049.

Atkinson. A. B. (1998). "Social Exclusion, Poverty and Unemployment" in A. B. Atkinson and J. Hills Exclusion, Employment and Opportunity, CASE Paper 4, London: Centre for Analysis of Social Exclusion, London School of Economics

Bista, Dor, B. (1992). Fatalism and Development: Nepal's Struggle for Modernization. Delhi: Oxford University Press 
Cameron, C. (2006). "Geographies of welfare and exclusion: Social Inclusion and Exception" in Progress in Human Geography 30, 3 (2006) Pp. 396-404

Conceptual Issues” in International Journal of Social Welfare 2007: 16: Pp. 1-9

Francis, P. (1997). "Social Capital, Civil Society and Social Exclusion" in Kothari, Uma and Matin Minouge (eds) "Development Theory and Practice: Critical Perspectives" Hampshire: Palgrave

Gaige, Fredrick H. (1975). Regionalism and National Unity in Nepal Berekely: Univerisy of California Press

Jackson, C. (1999). "Social Exclusion and Gender: Does One Size Fit All?” in The European Journal of Development Research 11(1), Pp. 125-146

Kabeer, N. n.d. Social Exclusion, Poverty and Discrimination: Towards An Analytical Framework

O’Brien, M and Sue Penna, (2007). "Social Exclusion in Europe: Some Conceptual Issues" in International Journal of Social Welfare” 2007:16. Pp.1-9

O’Reilly, D. (2005). 'Social Inclusion: A Philosophical Anthropology’ in Politics Vol. 25 (2), Pp.80-88

Pandey, T, S. Mishra, D. Chemjong, S. Pokhrel, N. Rawal (2006) Forms and Patterns of Discrimination in Nepal: A Report: Kathmandu, United Nations Educational Scientific and cultural Organization (UNESCO).
Pradhan, R. (2006) "Understanding Social Exclusion and Social Inclusion in Nepalese Context: Some Preliminary Remarks" in The Organisation Vol 9, Issue 3. Pp. i-xi

Sen, A. (2000). "Social Exclusion: Concept, Application and Scrutiny" in Social Development Paper No. 1, Asian Development Bank

Silver, H. (1994). "Social Exclusion and Social Solidarity: Three Paradigms” in International Labour Review,133 (5-6) Pp. 531578. 